\title{
Specific Permeability of Chiral Amino Acids through the Peptide Grafted
}

\author{
Poly ( $N$-isopropylacrylamide) Crosslinked Membranes
}

\author{
Meng Yu, Kenji Nagata and Masahiro Higuchi* \\ Department of Materials Science and Engineering, Graduate School of Engineering, Nagoya Institute of Technology, \\ Gokiso-cho, Shouwa-ku, Nagoya 466-8555, Japan \\ * Corresponding author: Fax \& Tel: 052-735-7156, E-mail: higuchi.masahiro@nitech.ac.jp
}

\begin{abstract}
We prepared amphiphilic peptide, $\left({ }_{\mathrm{L}}-\mathrm{Leu}_{-}-\mathrm{Lys}\right)_{8}$, grafted poly( $N$-isopropylacrylamide) crosslinked membranes which have the $\mathrm{pH}$ and thermo-responses in the MF-Millipore support films. The content of grafted peptide was fixed at $4 \mathrm{~mol} \%$ and the crosslinking degrees of the membranes were $1.5 \%$ and $16 \%$, respectively. We investigated the influence of the crosslinking degree on the $\mathrm{pH}$ and thermo-induced permeability and permselectivity of $\mathrm{L}^{-}$and ${ }_{\mathrm{D}}$-Phe through the membranes. Under the neutral condition $(\mathrm{pH}$ 6.5 , at $\left.20^{\circ} \mathrm{C}\right)$, the maximum permselectivity $(\alpha=2.6)$ and relatively high permeability $\left(P=2.86 \times 10^{-7} \mathrm{~cm}^{2} \mathrm{~s}^{-1}\right)$ were achieved in the high crosslinking degree membrane (16\%). Meanwhile, the low crosslinking degree membrane showed very high permeability $\left(P=3.2 \times 10^{-6} \mathrm{~cm}^{2} \mathrm{~s}^{-1}\right)$ under this condition. In the high crosslinking degree membrane, the peptide graft chains formed $\beta$-sheet domain. The domain acted as the selective permeable path for ${ }_{\mathrm{L}}-\mathrm{Phe}$. On the other hand, In the low crosslinking membrane, the grafted peptide chains, which were fixed on the flexible poly( $N$-isopropylacrylamide) main chains, could not form the $\beta$-sheet domain result in the high permeability and low perselectivity of the Phe.
\end{abstract}

Key words: peptide, poly( $N$-isopropylacrylamide $)$ membrane, temperature and $\mathrm{pH}$ sensitive, permeability

\section{INTRODUCTION}

The biological responses such as therapeutic activity for the drug molecules are strongly dependent on the chirality of the drugs [1]. For example, D-propoxyphene acts as a narcotic analgesic and prescribed for the relief of moderate pain from surgery or major injuries, while ${ }_{L}$-propoxyphene enantiomer has antitussive properties. The use of enantiopure pharmaceuticals and fine chemicals is very important to avoid the side effect. The separation of racemic mixture to obtain the one of the enantiomer of the drug using membrane separation technique is expected for its high efficiency, low energy usage, simplicity, and continuous operability [2]. Among membrane systems, polymer membranes containing amino acid have widely studied. In the previous study, we reported [3] that the poly
( ${ }_{\mathrm{L}}$-Leu) grafted polyallylamine formed a stable and regular molecular membrane having a $\beta$-sheet structure under the acidic condition. The permeability of ${ }_{L}$-Leu through the molecular membrane is larger than that of D-Leu by a factor of 26 . In this study, we prepared $\left({ }_{\mathrm{L}} \text {-Leu-L-Lys }\right)_{8}$ grafted poly $(N$-isopropylacrylamide) crosslinked membranes having $\mathrm{pH}$ and thermo-responses. We investigated the influence of the crosslinking degree on the $\mathrm{pH}$ and thermo-induced permeability and permselectivity changes through the membranes.

\section{EXPERIMENTAL}

2-1 Preparation of the peptide grafted PNIPAm crosslinked membranes in the support films The peptide ( $\mathrm{L}_{\mathrm{L}}$-Leu-${ }_{\mathrm{L}}$-Lys) ${ }_{8}$-vinyl ((LK) ${ }_{8}$-vinyl) was 
synthesized by the solid phase peptide synthesis (SPPS) [4]. The peptide grafted PNIPAm crosslinked membranes in the support films were obtained as follows. $10 \mathrm{mg}$ of $N$-isopropylacrylamide (NIPAm)

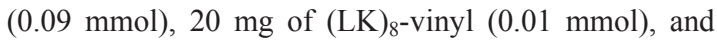
$0.5 \mathrm{mg}$ or $1.5 \mathrm{mg}$ of $N, N^{\prime}$-methylenebisacrylamide as cross-linker were dissolved in $1 \mathrm{ml}$ of water and stirred in a $10 \mathrm{~mL}$ flask at room temperature, respectively. Then $100 \mu \mathrm{L}$ acetone solution of photoinitiator (containing 2-Hydroxy-2-methylpropiophenone $10 \mu \mathrm{L}$ ) were added into the monomer solutions. Freeze-deaeration was carried out three times to remove the oxygen. The MF-Millipore membrane filters (MF, thickness $180 \mu \mathrm{m}$, pore size $0.22 \mu \mathrm{m}$, porosity $75 \%$ ) were immersed in the reaction mixtures to impregnate the monomer solution in the pore of the membranes. And then the films were put on Teflon dishes in glove box. The polymerization was occurred by UV irradiation in the ice-water bath for $2 \mathrm{~h}$. After the polymerization, the membranes were immersed in the pure water to remove the unreacted monomer and the crosslinking agent.

\section{2-2 Characterization of the peptide grafted membrane}

We also synthesized the membranes without the support films at the same condition to characterize the composition, degree of hydration, and conformation of the membrane.

From the elemental analysis of the two crosslinked membranes, we obtained the contents of the peptide graft chain and the crosslinker. The graft content of the both membranes was $4 \mathrm{~mol} \%$. The crosslinking degrees of the membranes were $1.5 \%$ (low-crosslinked) and $16 \%$ (high-crosslinked), respectively.

The degree of hydration $(H)$ of the membranes were calculated from the equation $H=\left(\mathrm{M}_{\mathrm{S}}-\mathrm{M}_{0}\right) / \mathrm{Ms}$, where $M_{S}$ is the weight of swollen membrane and $M_{0}$ is the weight of dried membrane. The membranes were swollen in aqueous solution under various conditions ( $\mathrm{pH}$ and temperature), blotted, and weighed and measured repeatedly until constant weigh obtained.

The conformations of the peptide graft chains in membrane were investigated by means of Transmittance
Fourier transform infrared (TM-FTIR) spectroscopy (Perkin-Elmer Spectra 2000). The membranes were dipped in aqueous solutions at various $\mathrm{pH}$ conditions at $20^{\circ} \mathrm{C}$ until the membrane weight reached a constant value and quickly frozen in liquid nitrogen, and then the frozen samples were lyophilized to obtain the dried membrane powders. The pellet for TM-FTIR measurement was prepared by the mixing of the membrane powder and $\mathrm{KBr}$. The weight fraction of the membrane was fixed at $1 \mathrm{wt} \%$.

The permeability measurements of the Phe through the crosslinked membranes were carried out with a Pyrex glass permeation cell. $5 \mathrm{mM}$ aqueous solution of L-Phe or ${ }_{\mathrm{D}}$-Phe was introduced into one side of the cell, and the Phe free water was taken into the other side (the permeated side) of the cell. The changes in the Phe concentration with time on the permeated side were measured with an UV-vis spectrophotometer (UV-3600, Shimadzu, Japan), from the absorbance at $256.5 \mathrm{~nm}$ on the basis of the molar extinction coefficient of the phenylalanine.

The permeability coefficients $P\left(\mathrm{~cm}^{-2} \mathrm{~s}^{-1}\right)$ of $\mathrm{L}^{-}$and D-Phe were calculated by $P=\frac{d c}{d t} \cdot \frac{V \cdot \delta}{S \cdot \Delta c}$, where $\mathrm{dc} / \mathrm{dt}$ is the initial slope of the permeation curve, $\mathrm{V}$ is the volume of aqueous solution in permeated side, $\delta$ is the membrane thickness, $\mathrm{S}$ is the effective area of the membrane. The permeability measurements of $\mathrm{L}^{-}$and D-Phe were performed 3 times under the same condition, and the $P$ values for the $\mathrm{L}^{-}$and $\mathrm{D}^{-}$-Phe were obtained as an average value, $P_{\mathrm{D}}$ and $P_{\mathrm{L}}$, respectively. The permselectivity, $\alpha$, was defined from $\alpha=P_{\mathrm{L}} / P_{\mathrm{D}}$. The $\mathrm{pH}$ of the aqueous solution was adjusted with $0.1 \mathrm{M} \mathrm{HCl}$ and $0.1 \mathrm{M} \mathrm{NaOH}$.

\section{RESULTS AND DISCUSSION}

3-1 $\mathrm{pH}$ and thermo-induced hydration changes of the crosslinked membranes and conformational changes of the grafted peptides

Table 1 shows $\mathrm{pH}$ and thermo-induced hydration degree changes of the crosslinked membranes. The hydration degrees of the low-crosslinked membrane were obviously decreased above the LCST, $36{ }^{\circ} \mathrm{C}$, of 
Table I. Hydration degrees of crosslinked membranes under various conditions

\begin{tabular}{ccccc}
\hline \multicolumn{5}{c}{ Hydration degree / \% } \\
\hline & \multicolumn{2}{c}{ Low-crosslinked } & \multicolumn{2}{c}{ High-crosslinked } \\
& $20{ }^{\circ} \mathrm{C}$ & $40{ }^{\circ} \mathrm{C}$ & $20{ }^{\circ} \mathrm{C}$ & $40{ }^{\circ} \mathrm{C}$ \\
\hline pH 3.0 & 98.5 & 93.8 & 96.8 & 96.5 \\
pH 6.5 & 98.6 & 86.3 & 98.2 & 97.8 \\
pH 9.0 & 98.9 & 80.9 & 96.8 & 96.3 \\
\hline
\end{tabular}

the PNIPAm main chain. On the other hand, the thermo-induced hydration changes of the high crosslinked membrane were relatively lower than those of the low crosslinked membrane owing to the high crosslinking density.

The $\mathrm{pH}$ induced conformational changes of the graft peptides of the crosslinked membranes were characterized by the TM-FTIR spectra. We obtained the fraction of conformations, $\alpha$-helix, $\beta$-sheet, and random coil, from the ratio of integrated peak intensities assigned by peak deconvolution of the amide I band [5] (Table II). The graft peptides in the low crosslinked membrane took a mainly $\alpha$-helical conformation. On the other hand, in the high crosslinked membrane, the $\beta$-sheet contents of the graft peptides were increased. It is well known that the sequential alternating amphiphilic peptide takes a $\beta$-sheet conformation. In the low crosslinked membrane, the mobility of the PNIPAm main chain was high owing to the low crosslinking density compared with high high crosslinked membrane. The PNIPAm main chain disturbed the intermolecular hydrogen bonding among the graft peptides. This resulted in the low $\beta$-sheet contents.

3-2 Permeability changes of $\mathrm{L}^{-}$and ${ }_{\mathrm{D}}$-Phe through the crosslinked membranes in the support films by $\mathrm{pH}$ and thermal stimuli.

In the previous studies, we have reported that the $\beta$-sheet domain in the peptide molecular membrane acted as a binding site of amino acid, which had same chirality with the peptide [6]. And the domain acted as a selective permeation path through the membrane for the amino acid [3].

We investigated the permeability of $\mathrm{L}^{-}$and $\mathrm{D}^{-} \mathrm{Phe}$ through the peptide grafted crosslinked PNIPAm membranes in the support films. Figure 1 shows permeability coefficient of $\mathrm{L}^{-}$and $\mathrm{D}_{\mathrm{D}}$-Phe through the a); low crosslinked membrane, and b); high crosslinked membrane in the support film under the different $\mathrm{pH}$ and temperature conditions, respectively. In the case of low crosslinked membrane, the permeability coefficients were very high. The order of the permeability coefficients was $10^{-6} \mathrm{~cm}^{2} \mathrm{~s}^{-1}$ (self-diffusion constant of Phe is $\left.9.0 \times 10^{-6} \mathrm{~cm}^{2} \mathrm{~s}^{-1}\right)$. And the low crosslinked membrane did not show the permselectivity of $\mathrm{L}^{-}$and $\mathrm{D}^{-}$Phe (Fig 1c). The high permeability and low permselectivity of Phe through the low crosslinked membrane was due to flexible structure of the membrane, whose crosslinking degree was low. However, the permeability through the membrane was increased above LCST under the acidic and neutral $\mathrm{pH}$ conditions. Above LCST, the PNIPAm main chain was shrunk to form globular conformation. The conformational transition of PNIPAm main chain induced the formation of the pore, which was acted as the permeable path for both $\mathrm{L}^{-}$and $\mathrm{D}^{-}$-Phe. However, under the basic condition the permeability through the membrane did not change by the thermal stimuli. Under this condition, the deprotonated peptide graft chains formed disordered aggregate owing to the hydrophobic interaction in the membrane. The aggregate acted as

Table II. pH induced conformational changes of the graft peptide in the crosslinked membranes

\begin{tabular}{ccccccc}
\hline & \multicolumn{3}{c}{ Low-crosslinked } & \multicolumn{3}{c}{ High-crosslinked } \\
\cline { 2 - 7 } & $\alpha$-helix / $\%$ & $\beta$-sheet / $\%$ & Random / $\%$ & $\alpha$-helix / $\%$ & $\beta$-sheet / \% & Random / \% \\
\hline pH 3.0 & 54.8 & 12.9 & 32.3 & 34.9 & 37.2 & 27.9 \\
\hline pH 6.5 & 45.2 & 22.6 & 32.2 & 33.3 & 39.2 & 27.5 \\
\hline pH 9.0 & 40.8 & 26.5 & 32.7 & 30.3 & 36.4 & 33.3 \\
\hline
\end{tabular}


: L-Phe, $20^{\circ} \mathrm{C}$; o-Phe, $20^{\circ} \mathrm{C}$;
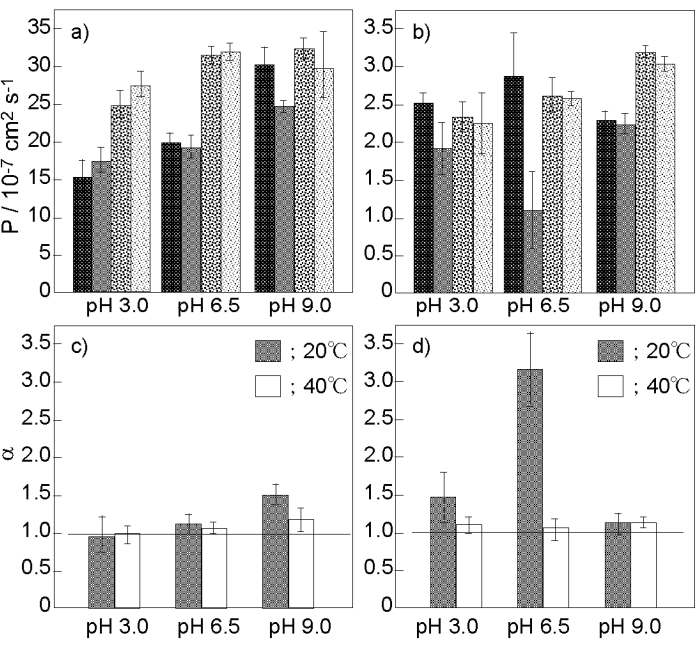

Figure 1. Permeability coefficients, $P$, of $\mathrm{L}^{-}$and $\mathrm{D}^{-P h e}$ through the a); low crosslinked membrane and b); high crosslinked membrane in the support film, respectively. c) and d) show the permselectivity, $\alpha$, of ${ }_{\mathrm{L}}$-Phe to ${ }_{\mathrm{D}}$-Phe through the low crosslinked membrane and high crosslinked membrane in the support film, respectively.

physical crosslinker in the membrane and formed permeable path by the disturbance of the homogeneous hydrated membrane structure.

On the other hand, permeability and permselectivity through the high crosslinked membrane showed different phenomenon under the neutral and acidic conditions (Fig 1b and 1d). Especially, under the neutral condition ( $\mathrm{pH}$ 6.5) and low temperature below LCST $\left(20{ }^{\circ} \mathrm{C}\right)$ the membrane show the relatively high permeability $\left(2.86 \times 10^{-7} \mathrm{~cm}^{2} \mathrm{~s}^{-1}\right)$ and permselectivity $(\alpha=2.9)$. Under this condition, the high crosslinked membrane was most swollen and the peptide graft chains were partially protonated (pKa of the peptide graft chain was 7.5). The electrostatic repulsion among the partially protonated peptide chains in the high crosslinked membrane disturbed the rapid formation of the disordered aggregation and aided in the formation of the considerable amount of $\beta$-sheet structure, which acted as permselective path for the ${ }_{\mathrm{L}}$-Phe. Furthermore the permeant, Phe, was negatively charged (PI of Phe was 5.48). The attractive force between the negatively charged Phe and positively charged $\beta$-sheet domain induced the increase of the partition of ${ }_{\mathrm{L}}$-Phe to the membrane. That is to say, the $\beta$-sheet domain composed of ${ }_{\mathrm{L}}$-amino acid in the membrane acted as effective binding site and permeable path for the ${ }_{\mathrm{L}}$-Phe. With the increasing in temperature above $\operatorname{LCST}\left(40{ }^{\circ} \mathrm{C}\right)$, the PNIPAm main chain was dehydrated and the crosslinked membrane was shrunk in the support film to form the void. The void acted as the non-selective permeable path for both $\mathrm{L}^{-}$and $\mathrm{D}^{-}$-Phe.

Under the acidic condition, the high crosslinked membrane did not show the permselectivity. Under the acidic condition, peptide graft chain and permeant, Phe, had positive charge. The electrostatic repulsion between the membrane and permeant disturbed partition of the Phe to the membrane and resulted in the same permeability of $\mathrm{L}^{-}$and ${ }_{\mathrm{D}}$-Phe through the membrane above and below LCST.

In conclusion, we have prepared the peptide grafted PNIPAm crosslinked membranes supported by MF films with different crosslinking degree. The membranes showed different conformational changes and permeability responsive to $\mathrm{pH}$ and temperature stimuli. These two membranes achieved highest permeability or permselectivity separately. For the further research we will investigate different composition of peptide grafted membrane to balance these two factors that is useful in practical applications.

Reference

[1] N. M. Maier, P. Franco, and W. Lindner, $J$. Chromatogr. A, 906, 3-33 (2001).

[2] C. A. M. Afonso, and J. G. Crespo, Angew. Chem., Int. Ed., 43, 5293-5295 (2004).

[3] M. Higuchi, and T. Kinoshita, Chemphyschem., 9, 1110-1113 (2008).

[4] M. Yu, T. Tang, A. Takasu, and M. Higuchi, Polym. J. 46, 52-58 (2014).

[5] T. Miyazawa, and E. R. Blout, J. Am. Chem. Soc., 83, 712-719 (1961).

[6] M. Higuchi, J. P. Wright, K. Taguchi, and T. Kinoshita, Langmuir, 16, 7061-7065 (2000).

(Received December 18, 2013; Accepted May 23, 2014) 